\title{
A EXPERTISE DE NIGHTINGALE E O MANUAL BRASILEIRO DE ACREDITAÇÃO DE ORGANIZAÇÕES DE SAÚDE
}

Leila Soares Seiffert ${ }^{1}$, Lillian Daisy Gonçalves Wolff², Marilene Loewen Wall ${ }^{3}$

\begin{abstract}
RESUMO: Reflexão sobre a expertise e a contribuição de Florence Nightingale para a prática da enfermagem e para a segurança do paciente. São realizadas analogias entre concepções da referida autora acerca de doentes, enfermagem, ambiente hospitalar e os itens de orientação do Manual Brasileiro de Acreditação de Organizações Prestadoras de Serviços de Saúde, versão 2006, especificamente os relativos ao Nível 1. A abordagem epidemiológica, a compreensão e ênfase da necessidade de conhecimento científico de Nightingale são atuais e refletem a importância, por ela atribuída, à prevenção de riscos, medidas e avaliação de fenômenos em busca da qualidade da assistência e à segurança do paciente, preceitos incluídos no Manual Brasileiro de Acreditação, que destaca a segurança, a qualidade da assistência, o aprimoramento da gestão e a qualificação das equipes.

PALAVRAS-CHAVE: Enfermagem; Prática profissional; Acreditação.

\section{NIGHTINGALE'S EXPERTISE AND THE BRAZILIAN MANUAL OF ACCREDITATION BY HEALTH ORGANIZATIONS}

\begin{abstract}
This is a reflection on Florence Nightingale's expertise and contribution to the practice of nursing and the safety of the patient. Analogies are made between her views concerning patients, nursing and hospital environments and the orientation items in the Brazilian Manual of Accreditation for Health-Service-Providing Organizations (2006 edition) specifically those relating to Level 1 . The epidemiological approach, understanding and emphasis on the need for scientific understanding shown by Nightingale have not become outdated and reflect the importance she attributed to risk prevention, rules and evaluation of phenomena in search of quality of care and patient safety. These are to be found in the Brazilian Manual of Accreditation, which emphasizes safety, quality of care, the improvement of management and the qualification of teams. KEYWORDS: Nursing; Professional practice; Accreditation.

\section{LA EXPERTISE DE NIGHTINGALE Y EL MANUAL BRASILEÑO DE “ACREDITAÇÃO” DE ORGANIZACIONES DE SALUD}

RESUMEN: Reflexión sobre la expertise y la contribuicción de Florence Nightingale para la práctica de la enfermería y para la seguridad del paciente. Son realizadas analogías entre concepcciones de la mencionada autora acerca de enfermos, enfermería, ambiente hospitalar y los ítenes de orientación del Manual Brasileño de "Acreditação" de Organizaciones Prestadoras de Servicios de Salud, versión 2006, específicamente los relativos al Nivel 1. El abordaje epidemiológico, la comprensión y énfasis de la necesidad de conocimiento científico manisfestado por Nightingale son actuales y refleten la importancia atribuida por ella a la prevención de riesgos, medidas y evaluación de fenómenos en búsqueda de la cualidade de la asistencia y de la seguridad del paciente. Estes están en el Manual Brasileño de "Acreditação", que destaca la seguridad, la cualidade de la asistencia, el perfeccionamiento de la administración y la cualificación de los equipos.

PALAVRAS-CLAVE: Enfermería; Práctica profesional; Acreditación.

\footnotetext{
*Trabalho apresentado à Disciplina "Concepções Teórico-Filosóficas e Metodológicas para a Prática Profissional em Enfermagem", do Programa de Pós-Graduação em Enfermagem da Universidade Federal do Paraná - PPGENF UFPR.

${ }^{1}$ Enfermeira. Mestranda pelo PPGENF UFPR. Membro do Grupo de Pesquisa em Políticas, Gestão e Práticas em Saúde - GPPGPS. ${ }^{2}$ Enfermeira. Doutora em Engenharia da Produção. Professora do Departamento de Enfermagem e do PPGENF UFPR. Líder do GPPGPS. ${ }^{3}$ Enfermeira. Doutora em Filosofia da Enfermagem. Professora do Departamento de Enfermagem e do PPGENF UFPR. Membro do Núcleo de Pesquisa e Extensão em Cuidado Humano de Enfermagem - NEPECHE.
} 


\section{INTRODUÇÃO}

No ano de 2010, a Organização das Nações Unidas comemorou o centenário de morte da fundadora da Enfermagem como profissão - Florence Nightingale (1820-1910), nomeando esse ano como o Ano Internacional da Enfermagem. Ao explorar a biografia de Nightingale e conhecer as suas observações sobre a Enfermagem, o processo de doença e o ambiente hospitalar, reconhece-se que temas tratados no Manual Brasileiro de Acreditação de Organizações Prestadoras de Serviços de Saúde, versão 2006 ${ }^{(1)}$, já eram considerados no plano de atuação de Nightingale nas instituições e em seus estudos.

Internacionalmente, a Acreditação é o mais difundido método de avaliação externa, realizada por pares, no campo da saúde. De caráter voluntário, periódico e reservado, ela inclui aspectos de estrutura, processo e resultados; baseia-se em padrões previamente conhecidos e três níveis de complexidade crescente, de modo que para alcançar a certificação de acreditação nos segundo e terceiro níveis é necessário atender aos padrões do(s) nível (is) antecedentes ${ }^{(1-2)}$.

O princípio orientador do Nível 1 é a Segurança, do Nível 2, a Gestão de Processos e do Nível 3, a Excelência na Gestão. Este artigo de reflexão teve por objetivo comparar 11 itens de orientação do Nível 1 com observações publicadas por Nightingale sobre o ambiente hospitalar e Enfermagem, tendo em vista evidenciar a expertise e a contribuição de Florence Nightingale para a prática da enfermagem e para a segurança do paciente.

\section{A expertise de Florence Nightingale}

Filha de pais ingleses abastados, Nightingale nasceu em Florença, em 1820. Recebeu educação esmerada e estudou vários idiomas, artes, matemática e estatística, filosofia, história e religião ${ }^{(3)}$. Atuou na Guerra da Criméia, em 1854, em um hospital militar improvisado e com condições sanitárias precárias, com excesso de feridos, falta de acomodações e suprimentos para alimentação e higiene, com uma mortalidade em torno de $40 \%$. Organizou o hospital, ganhou reputação de administradora e reformadora de hospitais e, em seis meses, reduziu a mortalidade para $2 \%$. Após dois anos, retornou à Inglaterra, como uma figura popular, símbolo de eficiência e heroísmo ${ }^{(3-4)}$. Essa experiência contribuiu para transformar a visão da sociedade em relação à participação da mulher no exército e à Enfermagem.
Florence criou a primeira Escola de Enfermagem, em 1860, junto ao Hospital Saint Thomas, em Londres, sob a filosofia de que a Enfermagem ajuda a pessoa a viver ${ }^{(5)}$. Adotou critérios para a educação de enfermeiras, com os objetivos de: fundação e direção de novas escolas por enfermeiras; ensino metódico através da prática; e seleção das candidatas sob o ponto de vista físico, moral, intelectual e de aptidão profissional $^{(4)}$. Nightingale era também consultada para analisar planos de construção de novos hospitais, instalações e equipamentos, assim como para estabelecer rotinas da administração.

Nightingale definiu Enfermagem como o ato de cuidar, que proporcionava à pessoa a melhor condição possível para que a natureza pudesse restaurar ou preservar sua saúde, prevenir e curar doenças ou ferimentos ${ }^{(5)}$. Entre as inúmeras contribuições para a prática profissional da Enfermagem destacam-se as recomendações de que as enfermeiras mantivessem um sistema de relato de óbitos, analisados estatisticamente, para identificar a incidência e causas das mortes dos soldados, causadas pelas condições insalubres. Com a sistematização de práticas de arquivos e registros, ela introduziu medidas inovadoras na higiene, como o uso de desinfetantes, e prevenção da infecção cruzada ao agrupar pacientes de acordo com o tipo de ferida e doença. Ela também priorizava o atendimento aos casos mais graves mediante classificação de risco. E, ainda, por meio de estudos retrospectivos, identificava quais tipos de pacientes seriam beneficiados pela assistência prestada, na tentativa de criar modelos de atendimento ${ }^{(5)}$.

A inovação se mostrava presente na maioria de suas propostas para a melhoria da saúde. Especificamente, do ponto de vista do uso da estatística em saúde Florence criou o Diagrama de Área Polar, que apresenta os dados estatísticos em forma de cunha ou pizza, de modo a favorecer uma melhor visualização; salienta-se que este instrumento é utilizado, atualmente, na gestão da qualidade em saúde.

Além da educação, suas contribuições elevaram o status da profissão e da qualidade da assistência de enfermagem ${ }^{(6)}$. Destaca-se que Nightingale "[...] foi protagonista de um projeto social de saúde que operacionalizou idéias modernizadoras na enfermagem, tornando-se imprescindível referenciá-la ao abordar o ensino da administração em enfermagem"(7:8), principalmente no tocante ao gerenciamento da infraestrutura, visando a segurança do paciente e a qualidade da assistência. 
O Manual da Organização Nacional de Acreditação - ONA

Lançado pela ONA, em 1999, o Manual Brasileiro de Acreditação das Organizações Prestadoras de Serviços de Saúde ${ }^{(1)}$ compõe-se de seções e subseções nas quais há padrões interdependentes que devem ser cumpridos integralmente pelas organizações que almejam a certificação de qualidade emitida por essa organização certificadora. O manual tem se atualizado ao longo do tempo. Passou por seis versões, sendo que a vigente é a de 2010.

Essa certificação é almejada por instituições de saúde, como diferencial dentre as demais. As conformidades, por padrões da ONA, têm como foco a segurança, a qualidade da assistência, o aprimoramento da gestão e a qualificação das equipes.

Os itens das seções do Manual são facilmente verificáveis, avaliando aspectos de estrutura, processo e resultado de um único serviço, e considerando uma atenção à saúde segura e efetiva ${ }^{(8)}$. O Manual contempla três níveis de complexidade crescente, com princípios orientadores específicos ${ }^{(5)}$, os quais norteiam a avaliação bem como a preparação da instituição para a avaliação ${ }^{(1)}$. Neste artigo, serão analisados e comparados os itens de orientação do Nível 1 , da versão de 2006 do manual, devido ao fato de a segurança do paciente e da equipe estarem fortemente relacionadas às condições adequadas de estrutura da organização. De acordo com o objetivo do presente artigo, este nível tem relação direta com os propósitos de administração de Nightingale,

\section{Os padrões do Nível 1 na perspectiva das observa- ções de Nightingale}

Os onze itens selecionados para a discussão relacionam-se a seis seções do Manual. Na seção Direção e Liderança, o padrão relaciona-se a atender aos requisitos formais, técnicos e de estrutura para o desenvolvimento de sua atividade, conforme legislação correspondente; dispor de responsável habilitado e/ou capacitado para a condução do serviço; identificar riscos específicos e gerenciá-los com foco na segurança ${ }^{(1)}$. Destacam-se os itens: evidência de responsabilidade técnica conforme a legislação e organização dos processos e sistemas voltados a assegurar o cumprimento das normas vigentes, bem como requisitos de segurança aos clientes e de gestão de recursos humanos. Sobre a importância da responsabilidade, Nightingale esclarecia que assumí-la é mais que se desincumbir pessoalmente de tarefas; é fazer que todos as realizem, assim como zelar para que ninguém atrapalhe ou impeça a sua realização, movido por decisão própria, ou por ignorância ${ }^{(9)}$.

A seção Organização Profissional agrupa as subseções relacionadas à organização do modelo institucional e dos profissionais responsáveis pelos processos finais, quais sejam, os do Corpo Clínico, de Enfermagem e o Corpo Técnico Profissional. Destaca-se, na subseção Enfermagem, o item Corpo de Enfermagem, que deve ser habilitado e capacitado. Nightingale frisa a importância da educação de uma enfermeira, fundamentada na relação com o ser humano doente ${ }^{(9)}$.

Na seção Atenção ao Paciente/Cliente encontramse, na subseção Assistência Nutricional os itens referentes à relação e prescrições de dietas básicas e cardápios destinados aos pacientes com patologias de maior prevalência, utilização de manual de boas práticas de preparo de alimentos, sistemática de visita e acompanhamento aos clientes/pacientes. Nightingale afirmava que a desnutrição e dificuldades para deglutir podem ser minimizadas com dieta prescrita e administrada adequadamente ${ }^{(9)}$.

Na seção Apoio Técnico destaca-se o item Cumprimento das Diretrizes da Comissão de Controle de Infecção por serviços e atividades, e na seção Abastecimento e Apoio Logístico destacam-se a subseções Qualidade da água e Higiene ${ }^{(1)}$. Para Nightingale a limpeza e o ar puro previnem infecção, mas a verdadeira Enfermagem, previne a infecção mediante assistência criteriosa e humana ao doente. Nightingale percebia que, havia relação entre a qualidade da água, sujeira e epidemias e portanto, era enfática quanto às condições sanitárias do ambiente, recomendado limpeza dentro e fora de casa ${ }^{(9)}$.

Entende-se que a principal contribuição de Nightingale refere-se à seção Infraestrutura. A subseção Gestão de Projetos Físicos contempla o planejamento de obras, que visa assegurar aos clientes conforto, condições de habitabilidade e segurança. A condição de habitabilidade também está associada à iluminação ${ }^{(1)}$. Sobre o arejamento e aquecimento, a autora considerava que a primeira regra de enfermagem é conservar puro o ar do ambiente em que está o paciente, o que pode ser proporcionado por um bom projeto físico que viabilize ventilação adequada, prevenindo assim a estagnação do ar e a provável imediata instalação de doenças ${ }^{(9)}$. Nesse sentido, a pioneira recomendava que os projetos definissem espaços funcionais aos pacientes e enfermeiras, e que as questões de saneamento fossem priorizadas $^{(5)}$. Nightingale referia, ainda, que um local 
escuro é sempre insalubre, quase sempre mal arejado e sujo, prejudicando a saúde das pessoas e o completo restabelecimento quando estão enfermas ${ }^{(9)}$.

Na subseção Gestão da Manutenção Predial, destacam-se os itens que se referem ao Gerenciamento, operação e controle dos sistemas de água, energia elétrica, vapor, efluentes líquidos, proteção contra descarga elétrica, climatização, combate a incêndio, alerta e emergência, telefonia e rede lógica, de acordo com o porte e necessidades do serviço ${ }^{(1)}$. Nightingale já se preocupava com as consequências da má infraestrutura na recuperação dos doentes. Sobre a temperatura ambiente, por exemplo, alertava que manter o quarto aquecido, à custa de obrigar o doente a respirar sempre a mesma atmosfera quente, úmida e pútrida, era a maneira certa de retardar a cura ou destruir a vida. Quanto aos efluentes líquidos, relacionava-os à disseminação de febres ou septicemias e comentava a insalubridade das moradias que possuíam canalização exposta, com comunicação para o esgoto ${ }^{(9)}$.

\section{CONSIDERAÇÕES FINAIS}

A avaliação de acreditação busca evidenciar, de forma consistente, se os processos institucionais estão organizados de maneira a constituir barreiras para prevenir, evitar e minimizar os riscos aos pacientes e aos profissionais. $\mathrm{O}$ Nível 1 da Acreditação enfoca a segurança, confluindo para o alerta de Nightingale de que a função dos hospitais, é prioritariamente, não causar dano ao paciente.

As observações e ideias da autora continuam atuais, seja pela abordagem epidemiológica das doenças e infecções, seja pela compreensão e ênfase da necessidade de conhecimento científico ou pelo respeito que demonstrava pela pessoa adoentada. $\mathrm{Na}$ análise realizada, comparando-as aos itens de orientação do Manual de Acreditação, verificou-se, na literatura disponível, a preocupação de Florence Nightingale com a segurança do paciente e recomendações para a prevenção de riscos, medidas e avaliações de fenômenos na área da saúde, mediante estatísticas.

Nightingale destacou-se como uma mulher com ideias inovadoras e com conhecimentos em áreas diversificadas, tais como a higiene do ambiente, a engenharia e a arquitetura. Sua experiência bem sucedida em coordenar e conduzir o esforço para a segurança do paciente no século XIX continua sendo um desafio para enfermeiros que assumem, atualmente, a gerência da assistência e dos serviços de saúde, bem como para os alunos do Curso de Graduação em Enfermagem.

\section{REFERÊNCIAS}

1. Organização Nacional de Acreditação (ONA). Manual das organizações prestadoras de serviços de saúde. Brasília; 2006.

2. Novaes HM, Paganini JM. Garantia da qualidadeacreditação de hospitais para América Latina e Caribe. Brasília: Organização Pan-Americana de Saúde/Federação Brasileira de Hospitais; 1992.

3. Carraro TE. Enfermagem e assistência: resgatando Nightingale. Goiânia: AB; 1997.

4. Paixão W. História da enfermagem. $5^{\mathrm{a}}$ ed. Rio de Janeiro: Julio C. Reis; 1979.

5. Campos ACB. Avaliação de uma instituição hospitalar com base no programa de acreditação hospitalar [dissertação]. Santa Maria (RS): Universidade Federal de Santa Maria; 2006.

6. Oguisso T, organizador. Trajetória histórica e legal da enfermagem. Barueri: Manole; 2005.

7. Massaro M, Chaves LDP. A produção científica sobre gerenciamento em enfermagem hospitalar: uma pesquisa bibliográfica. Cogitare Enferm. 2009;14(1):150-8.

8. Quinto Neto A, Gastal FL. Acreditação hospitalarproteção dos usuários, dos profissionais e das instituições de saúde. Porto Alegre: Dacasa; 1997.

9. Notas sobre enfermagem: o que é e o que não é. Trad. de Amália Correa de Carvalho. São Paulo: Cortez/ ABEn-CEPEn; 1989. 